\title{
PROJETOS SOLIDÁRIOS: UM CASO DE EXTENSÃO UNIVERSITÁRIA PARA GRUPOS DA TERCEIRA IDADE
}

\author{
SOLIDARY PROJECTS: A CASE OF UNIVERSITY EXTENSION \\ FOR THIRD AGE GROUPS
}

Carlyle Tadeu Falcão de Oliveira ${ }^{1}$

Norma Suely da Silva Chavão ${ }^{2}$

Priscila Burini Correia ${ }^{3}$

\begin{abstract}
RESUMO
A importância da extensão universitária na articulação do movimento de Economia Solidária para explorar novas alternativas favoráveis ao desenvolvimento social e produtivo, também pode ser pensada para grupos da Terceira Idade. Este artigo, teve como objetivo explorar e descrever um projeto de extensão universitária, no Centro de Convivência da Universidade Aberta da Terceira Idade da Universidade Estadual do Rio de Janeiro (UnATI-UERJ). A relevância do estudo está na reflexão sobre o conceito de Tecnologia Social, no campo da Administração, hoje muito pouco estudado e como ela pode aproximar os saberes da universidade e da sociedade, sob a perspectiva de um futuro mais inclusivo. Para tanto, o estudo procedeu a uma observação-participante durante o curso de extensão universitária denominado Projetos Solidários ministrado na UnATI-UERJ. Os resultados deste projeto de extensão destacam que a transferência de Tecnologia Social pode contribuir para a articulação entre os saberes desenvolvidos no ambiente acadêmico e os saberes locais, visando à formação e capacitação de alunos da terceira idade em economia solidária e projetos comunitários, proporcionando a esses indivíduos um fortalecimento da sua cidadania e perspectivas de melhorias de qualidade de vida.
\end{abstract}

Palavras-chaves: Extensão Universitária; Tecnologia Social; Economia Solidária.

\begin{abstract}
The importance of university extension in the articulation with the Solidarity Economy movement to explore new alternatives favorable to social and productive development for excluded or deprived segments can also be thought for Third Ages groups. The purpose of this article was to explore and describe the university extension project at the Open University of the Third Age Open University of Rio de Janeiro (UnATI-UERJ). The relevance of the study lies on the reflection of the Social Technology concept considering the Administration knowledge area, which is very little studied today, and how it can bring closer the university knowledgeand the society knowledge in a perspective of more inclusive

${ }^{1}$ Pós-doutor em Administração pela Universidade Federal Fluminense. Doutor em Administração pela EBAPEFGV. Professor Adjunto da Faculdade de Administração e Finanças da Universidade do Estado do Rio de Janeiro - UERJ. e-mail: carlyle.falcao@gmail.com

${ }^{2}$ Graduada em Administração pela UFRRJ e mestranda em Administração pelo PPGAd-UFF.

${ }^{3}$ Licenciada em História pela Universidade Gama Filho e graduanda em Administração pela UERJ
\end{abstract}


future. Therefore, the study made a participant observation during the university extension course called Solidary Projects given at UnATI-UERJ. The results of this extension project point out that the transfer of Social Technology can contribute to the articulation between the knowledge developed in the academic environment and the local knowledge, aiming at the training and qualification of senior citizens in solidarity economy and community projects, providing these individuals with a strengthening of their citizenship and prospects for improvements in quality of life.

Keywords: University Extension; Social Technology; Solidarity economy.

\section{INTRODUÇÃO}

O avanço da tecnologia afetou a sociedade em todas as dimensões, porém, segundo as Nações Unidas este avanço não garantiu um crescimento econômico inclusivo, sustentável e de trabalho decente para todos. Na agenda global, alternativas que ofereçam um contraponto à competitividade acirrada, ao consumo desenfreado, aos problemas sociais e as demais mazelas que assolam a sociedade moderna vem sendo discutidas. No Brasil vivemos uma crise sem precedentes, onde o nível de desemprego avança para todos os segmentos da sociedade, seguindo uma tendência mundial.

Recentemente publicado pela consultoria McKinsey \& Company, por meio de um relatório, dados surpreendentes demonstram a movimentação da força de trabalho em função do avanço tecnológico. Segundo o relatório, devido a novas tecnologias, perto de 375 milhões de profissionais perderão sua profissão ou mudarão de atividade. Isso representaria perto de 14\% da força global de trabalho (MORGADO \& PLIOPAS, 2018, p.13).

Associado ao tema do desemprego temos o fator do envelhecimento populacional, que no Brasil, vem acontecendo de forma acelerada. Segundo projeções do IBGE (2013) o aumento na participação relativa do grupo de idosos passará de 13,8\%, em 2020, para 29,4\%, em 2050.

A partir deste cenário preditivo, onde a capacidade técnica, passível de ser substituída por novas tecnologias, e o envelhecimento populacional pode aumentar ainda mais os segmentos de excluídos da economia tradicional, tornando necessárias ações e temas que possam influenciar na geração de trabalho e renda para estes segmentos, impulsionando assim uma nova economia fundamentada na produção, oferta de serviços, comercialização, finanças ou consumo baseado na democracia e na cooperação, pilares de outro tipo de economia, a economia solidária. 
Podemos também considerar o desenvolvimento de tecnologias sociais, que tem como principal definição serem produtos, técnicas e/ou metodologias reaplicáveis, na interação com a comunidade e que representem soluções efetivas de transformação social (DAGNINO, 2011), passando a fazer parte da agenda de trabalho a ser desenvolvida e compartilhada entre os países em desenvolvimento.

No Brasil, aquilo que se chama de tecnologia social é parte de um todo maior que compreende a economia solidária (ES) e a extensão universitária tecnológica, por meio das Incubadoras Tecnológicas de Cooperativas Populares - ITCPs (CRUZ, 2017), constitui parte da Política Nacional de Tecnologia Social com o objetivo de promover, potencializar, organizar, desenvolver, fomentar e fortalecer as atividades de tecnologia social.

A universidade possui um papel vital no debate sobre a exclusão, participando da construção de alternativas e apontando caminhos. Por ser uma instituição criada pela própria sociedade, relaciona-se diretamente com ela de modo que as questões alarmantes da sociedade são igualmente as da universidade (HECKERT, 2004).

Orientados pela investigação do papel da universidade no suporte à Economia Solidária e à Tecnologia Social no estado do Rio de Janeiro, Oliveira, Teles, Rodrigues e Chavão (2018) buscaram identificar quais ações universitárias têm sido realizadas envolvendo esses temas, incluindo também o tema Gestão Social, pois entenderam que a Gestão Social é transversal à Tecnologia Social e à Economia Solidária.

Como achado da pesquisa, das 8 instituições entre federais, estaduais e privadas, verificou-se que a maioria das instituições fluminenses tem algum programa de ensino, extensão e pesquisa que trabalham em alguma dimensão a economia solidária, a tecnologia social e a gestão social. Quanto aos trabalhos acadêmicos, encontrados nessa pesquisa, esperava-se que a sua maioria tivesse sua origem em cursos de pós graduação, cujas abordagens relevantes fossem mais ligadas às Ciências Sociais Aplicadas - Administração, Ciências Econômicas, Serviço Social e outros - porém, identificou-se que grande parte das dissertações e teses eram oriundas de cursos de pós-graduação da área das Engenharias (OLIVEIRA, TELES, RODRIGUES E CHAVÃO, 2018). 
A pesquisa concluiu que ainda há um longo caminho a ser percorrido para se conquistar novos espaços nas universidades fluminenses, que permitam a integração dos pesquisadores universitários com comunidades na busca de solução dos problemas sociais, principalmente na oferta de cursos e projetos de extensão (OLIVEIRA ET AL., 2018).

Desse modo, este artigo tem o objetivo de explorar e descrever como se pode trabalhar a extensão universitária com grupos da Terceira Idade que envolvam os temas de Economia Solidária, Tecnologia Social e Gestão Social.

O objeto de estudo foi um grupo de terceira idade do Centro de Convivência da Universidade Aberta da Terceira Idade da Universidade Estadual do Rio de Janeiro (UnATIUERJ) que tem sido assistido por um projeto extensionista da UERJ, denominado Projetos Solidários, e um grupo de pesquisa da Universidade Federal Fluminense - UFF.

A relevância do presente artigo está na reflexão sobre projetos de extensão universitária para grupos de terceira idade utilizando-se os conceitos de transferência de Tecnologia Social, de Economia Solidária e de Gestão Social. Além da relevância acadêmica, podemos destacar a integração da graduação com a pós-graduação e a rede de duas instituições públicas de ensino para a realização deste projeto de extensão. Estão envolvidos no projeto, um laboratório de extensão da Faculdade de Administração e Finanças da Universidade do Estado do Rio de Janeiro (FAF-UERJ) e um Programa de Mestrado em Administração da Universidade Federal Fluminense (PPGAd-UFF).

Não se pode deixar de se destacar a importância do estudo no contexto no campo da gestão, uma vez que a ausência de tradição dentro do pensamento gerencial na abordagem de assuntos relativos ao social apresenta uma necessidade de constituição de saberes efetivamente interdisciplinares no tratamento de questões e realidades complexas (SCHOMMER \& FRANÇA FILHO, 2010). Por meio deste estudo, apresenta-se também um questionamento sobre o pensamento organizacional hegemônico, na medida em que se propõe a gestão social como uma alternativa teórica e prática à gestão estratégica (CANÇADO, TENÓRIO \& PEREIRA, 2012).

Este estudo é composto de 5 seções: nesta seção, a seção 1, apresenta-se o referencial teórico que busca explorar algumas das principais fontes sobre o tema. Na sequência, tem-se a 
seção 2que discorre sobre a metodologia utilizada para aprofundamento do tema, evoluindo para a seção 3, onde se expõe os resultados e discussões da pesquisa. Finalmente na seção 4 apresentam-se as considerações finais.

\section{REFERENCIAL TEÓRICO}

\subsection{Os conceitos que definem a Tecnologia Social (TS)}

Para dar início aos estudos das literaturas concernentes à TS e seu fomento pelas universidades federais, vê-se necessário passar por alguns conceitos e estudos que possam embasar as análises a serem realizadas, uma vez que o termo tecnologia social, seus diferentes usos e significados, foram associados à distintos termos com amplas interpretações, reunindo diferentes atores. O conceito propriamente dito, polissêmico, permanece em aberto porque tem sido acionado como uma categoria política, dado seu histórico e os valores que o informam (MARTINS, ANTUNES, PINHO DA SILVA \& PEREIRA DA SILVA, 2018).

A tecnologia como se conhece hoje está inserida na sociedade de tal forma que não paramos para nos questionar como ela dita a forma como a sociedade se desenvolve, a tecnologia (FREITAS \& SEGATTO, 2014) vem moldando os estilos de vida, que já não é possível tratá-la como um fenômeno isolado da dinâmica social cerceado por um debate reducionista de cunho técnico científico. E de que tecnologia estamos falando? O que a difere da TS objeto deste estudo? Para responder estas perguntas será necessário buscarmos fundamentar esse conceito e suas variações.

\subsubsection{A Tecnologia Convencional (TC)}

Para Dagnino (2014), a tecnologia convencional ou capitalista (TC) está intimamente ligada às inovações tecnológicas atuais, sendo a tecnologia que a empresa desenvolve, usa e precisa para diminuir seu custo de produção. A TC foi sendo desenvolvida e aprimorada, nos primórdios da revolução industrial, quando as tarefas e ambientes de trabalhos foram sendo reorganizados para redução da mão de obra e aumento da produtividade.

Nos tempos atuais, a TC está altamente voltada para o lucro e o consumo atingindo maior eficiência a cada evolução tecnológica e cada vez em maior escala, segundo Feenberger 
(1980). Esse autor atribui à TC a responsabilidade dos principais problemas da sociedade, dando a ela um valor substantivo e, não mais instrumental, pois são monopólio das grandes empresas, detentoras de capital para pesquisa e desenvolvimento. Para ele, a tecnologia é uma das maiores fontes de poder nas sociedades modernas, demonstrando assim um viés, aparentemente neutro, que está engajado em defesa de uma hegemonia.

Neste contexto, a TC seria comparável mais a uma religião do que ao dinheiro, porque é como a escolha de um meio de vida (LOPES, 2015). Além de tudo, ela é apontada como ambientalmente insustentável, porque não considera a deterioração do meio ambiente como custo (DAGNINO, 2014). Dentre as características da TC, o autor elenca ser mais poupadora de mão-de-obra do que seria conveniente, possuir escalas ótimas de produção sempre crescentes; ser ambientalmente insustentável, ser intensiva em insumos sintéticos produzidos por grandes empresas, ter sua cadência de produção dada pela máquina, possuir controles coercitivos que diminuem a produtividade, ser segmentada, não permitindo o controle do produtor direto, ser hierarquizada demandando a figura do proprietário e de um chefe, não utilizar a potencialidade do produtor direto, maximizar a produtividade em relação à mão-deobra ocupada, possuir padrões orientados pelo mercado externo de alta renda e ser monopolizada pelas grandes empresas dos países mais ricos (DAGNINO, 2014).

\subsubsection{A Tecnologia Apropriada}

Historicamente um dos grandes crítico da TC foi Gandhi, no final do século XIX, por meio dos programas comunitários de emancipação, como exemplo temos a popularização da roca de fiar que visava geração de renda e uma forma de luta contra as injustiças sociais e de castas da sociedade indiana da época (LASSANCE, BARBOSA, JARDIM, BRANDÃO \& NOVAES, 2004). Gandhi deu início ao chamado movimento de tecnologia apropriada (TA) que defendia a tecnologia moderna, com seus avanços científicos, porém adaptada a realidade local e meio ambiente, visando a transformação social e sustentabilidade. Apesar de praticá-la Gandhi nunca usou o termo TA, o mesmo foi introduzido no ocidente em 1973 por Schumacher, um economista alemão, inspirado nas ideias de Gandhi (LASSANCE ET AL., 2004), que definiu o conceito de uma tecnologia de baixo custo, pequena escala, simples e preocupada com o meio ambiente. Mais adequada aos países pobres ou em desenvolvimento, e nomeada de 
"tecnologia intermediária", uma vez que combinava elementos das tecnologias tradicionais com os das tecnologias avançadas (RODRIGUES \& BARBIERI, 2008), posteriormente se popularizou como TA. A TA teve um grande avanço nas décadas de 1970 e 1980, principalmente nos EUA, devido aos movimentos de grupos de pesquisadores partidários a TA que buscavam minimizar a pobreza nos países de terceiro mundo, demonstrando também preocupação com as questões ambientais e com as fontes alternativas de energia (LASSANCE ET AL., 2004).

A partir destas suas bandeiras, a TA, despertou interesse de importantes aliados, como por exemplo, no campo produtivo, as cooperativas e fábricas recuperadas; no político, os gestores das políticas sociais e de C\&T; no cognitivo, os professores, alunos e técnicos de institutos de pesquisa, em especial os que militavam nas incubadoras universitárias de cooperativas, bem como a OIT (Organização Internacional do Trabalho), que apoiou diversos estudos na Ásia e África (DAGNINO, BRANDÃO, \& NOVAES, 2010; DAGNINO, 2011; RODRIGUES \& BARBIERI, 2008). Contudo suas concepções também despertaram objeções e críticas por ser considerada uma tecnologia atrasada e constituir um instrumento para manutenção dos privilégios dos países ricos (RODRIGUES \& BARBIERI, 2008), uma vez que havia uma dinâmica de transferência de conhecimento dos países ricos para os países pobres após o esgotamento de uso das tecnologias nos países ricos. Para (DAGNINO, 2011) se a TA não fosse demandada por um ator com força política, ela permaneceria como uma curiosidade ou uma excentricidade tecnológica.

Apesar da tecnologia apropriada ter contribuído para o debate a respeito dos projetos de desenvolvimento nacionais e, em muitos países, para a própria luta de libertação nacional, como foi o caso da Índia, a TA, com seus objetivos políticos e sociais, perdeu força no cenário mundial, sendo abandonada pelos meios acadêmicos, empresariais e governamentais (RODRIGUES \& BARBIERI, 2008).

\subsubsection{A Tecnologia Social e sua interface com a Gestão Social}

É no cenário globalizado que o avanço da tecnologia vem afetando a sociedade em todas as dimensões, porém, segundo as Nações Unidas, este avanço não vem garantindo um crescimento econômico inclusivo, sustentável e de trabalho decente. Corroborando, Fonseca 
(2012) concluiu que um reflexo dos trabalhos de Estudos Sociais da Ciência e Tecnologia (ESCT) aponta que a ciência e a tecnologia perderam o status moderno de fonte de verdade e melhoria do bem estar social para serem reconhecidas como um mecanismo de exercício de poder que pode agravar problemas ambientais e sociais. Aponta-se, assim, para a necessidade de um modelo mais justo de gestão de Ciência e Tecnologia, com a participação do cidadão, abarcando nos processos de pesquisa e desenvolvimento de novas tecnologias, valores éticos, sociais e ambientais (FONSECA, 2012).

Neste contexto, Dagnino et al. (2010) conceituam como marco analítico-conceitual da TS, a reemergência de temas que antes eram associados a TA, como os movimentos das Redes de Economia Solidária (RESs), o das Incubadoras Tecnológicas de Cooperativas Populares (ITCPs), o movimento das empresas recuperadas e dos empreendimentos auto gestionários que se difundiram no mundo, principalmente no Brasil, como resposta aos desafios do milênio para um desenvolvimento inclusivo e sustentável

E o que são TSs? Algumas pessoas já ouviram falar, mas poucos se dão conta do que é chamado de tecnologia social. Elas estão disseminadas em várias áreas como saúde, educação, meio ambiente e muitas outras áreas. Para Lassance et al. (2004) algumas tão geniais, tão inovadoras e tão simples que provocam uma reação imediata nas pessoas: a de se perguntar por que não se pensou nisso antes. Como é o caso da TS Poste de Luz Solar, da ONG Litro de Luz, e que faz parte do banco de TS da Fundação do Banco do Brasil (FBB). Já implementado em cinco estados, tem a função de iluminar áreas públicas de comunidades que não possuem acesso à rede elétrica ou em casos em que ocorre queda de energia elétrica com frequência. Montada em uma caixa hermética acoplada ao corpo do poste, com uma lâmpada acionada por um circuito responsável, por meio de uma bateria, pela transferência da energia elétrica que é captada pela placa solar. A estrutura do poste é toda montada com canos de $p v c$ para facilitar a colocação de cimento para fixação no solo, e possibilitar a passagem de fiação elétrica. Finalmente, no topo é acoplada a placa solar e para a proteção do led é utilizada uma garrafa pet (https://fbb.org.br/pt-br/, recuperado em 26 de abril, 2019).

$\mathrm{Na}$ área de educação, a TS também se destaca pelo seu processo inclusivo e formativo, como é o caso da TS chamada Metodologia de incubação para empreendimentos de economia 
solidária, desenvolvida pela ITECSOL/UNIJUÍ e implantada em quatro bairros em Ijuí, no Rio Grande do Sul, que socializa a prática desenvolvida pela Incubadora de Economia Solidária, Desenvolvimento e Tecnologia Social/Itecsol Unijui, com o intuito de promover o crescimento econômico, inclusivo e sustentável, geração de trabalho digno e renda para grupos em vulnerabilidade social. Os resultados obtidos potencializam a socialização e replicação em outros empreendimentos econômicos solidários (https://fbb.org.br/pt-br/, recuperado em 26 de abril, 2019).

Neste caso, pode-se chamar a TS de um processo inovativo, de baixo custo e que traz uma autossuficiência local, uma vez que diminui a dependência dos órgãos públicos para a necessidade social da comunidade, isto é, leva em consideração os principais atributos da tecnologia apropriada:

Baixo investimento por posto de trabalho, baixo capital investido por unidade produzida, potencial de geração de empregos, simplicidade organizacional, pequena escala de produção, alto grau de adaptabilidade ao ambiente sociocultural, autossuficiência local e regional, economia no uso de recursos naturais, preferência pelo uso de recursos renováveis e controle social (RODRIGUES \& BARBIERI, 2008, p.1072).

A partir dessa definição pode-se retornar ao conceito de tecnologia social que permitirá entender a origem deste constructo, bem como é desenvolvido e como é difundido na sociedade. A TS pode ser definida como produtos, técnicas e/ou metodologias reaplicáveis, desenvolvidas na interação com a comunidade e que representam efetivas soluções de transformação social (DAGNINO, 2014; FBB, 2019).

Mesmo no campo das TSs, tradicionalmente, cabe aos engenheiros a função de produzir tecnologias dentro da universidade, distante da realidade dos empreendimentos de economia solidaria (EES), reproduzindo características da tecnologia convencional. O desenvolvimento de TS, por sua vez, implica repensar a forma de atuação do engenheiro (FRAGA, SILVEIRA \& VASCONCELLOS, 2008). Já para Bensadon (2008), é efetiva a necessidade da apropriação de ferramentas que auxiliem no controle, atuação e monitoramento do empreendimento, seja da contabilidade, das finanças e sobre a comercialização pelos seus participantes, ou seja, a autogestão, um dos pilares da economia solidária (SINGER, 2003). 
Nesse contexto, a concepção da tecnologia convencional está associada à gestão estratégica, que Tenório (2016) classifica como tecnoburocrática e monológica, devendo ser substituída por um gerenciamento participativo, dialógico, no qual o processo decisório em uma dada sociedade poderá ser exercido por diferentes atores sociais, caracterizando uma gestão democrática, isto é, uma gestão social.

A Gestão Social (GS) surge como uma nova possibilidade de gestão, no sentido de repensar as relações entre as pessoas e o próprio modelo de tomada de decisão. A GS é aqui entendida como um processo intersubjetivo que preside a ação da cidadania tanto na esfera privada quanto na esfera pública(TENÓRIO, 2016). Seu desenvolvimento enquanto campo do conhecimento da administração fornecerá os princípios para consolidar, desenvolver novas práticas em projetos sociais e proporcionar oportunidades quanto ao desenvolvimento de TS também no campo da administração.

A Gestão Social se desenvolve segundo a razão comunicativa, em que os atores expõem suas argumentações e o acordo é alcançado por meio de uma discussão crítica. Está presente o exercício da cidadania. Trata-se de uma ação política deliberativa, na qual o cidadão participa de um procedimento democrático decidindo o seu destino social, ou seja, pratica a cidadania deliberativa. Essa ação deliberativa acontece em um espaço social de diálogo entre sociedade civil, Estado e mercado, a esfera pública (TENÓRIO, 2016).

Borges et al (2007, 2008) nos mostram que a Gestão Social é indissociável da prática. Os autores apresentam experiências de projetos extensionistas que grupos desprovidos de conhecimento acadêmico são capazes de persistir em meio as adversidades e conseguem elaborar seus próprios projetos, segundo suas demandas comunitárias. Utilizou-se nessas experiências o embasamento teórico da tecnologia de projetos, mediada pelos ensinamentos da educação popular de Paulo Freire (2005) e Clodóvis Boff (1986).

\subsection{A Tecnologia Social no Brasil}

O termo tecnologia social, surge no Brasil na década de 1980, como um aprimoramento das Tecnologias Apropriadas, a partir da realidade de países em que elas eram criadas e não dos países ditos “de primeiro mundo", considerando o desenvolvimento sustentável e a participação ativa das comunidades locais. Por meio de uma ação articulada no âmbito do Comitê de 
Entidades no Combate à Fome e pela Vida (COEP), a COPPE/UFRJ, criou em 1995, com o apoio da Finep e da Fundação Banco do Brasil (FBB), a primeira Incubadora Tecnológica de Cooperativas Populares - ITCP. A missão deste projeto era desenvolver a metodologia de incubação de cooperativas populares e de difusão desta tecnologia social (TS) para outras universidades do país. Em 1997 foi criado o PRONINC - Programa Nacional de Incubadoras de Cooperativas Populares, tendo como signatários a Finep, o Banco do Brasil, a FBB e o COEP (SINGER, 2009).

Em 2003, segundo informações do Núcleo Interdisciplinar para Desenvolvimento Social (NIDES, 2019), já eram 33 incubadoras organizadas em duas redes e o PRONINC deu apoio material a todas as incubadoras, tanto para dar continuidade à incubação como para ajudar a criar novas incubadoras. A partir de 2013, dez anos depois, o programa passou para um novo formato de implementação, com a parceria entre a Secretaria Nacional de Economia Solidária (SENAES), o Conselho de Desenvolvimento Científico e Tecnológico (CNPq) e a Secretaria de Ciência e Tecnologia para Inclusão Social, do Ministério de Ciência, Tecnologia e Inovação (SECIS/MCTI). Tinha como objetivo selecionar, por meio de chamada pública, propostas para apoio financeiro a projetos de pesquisa, desenvolvimento tecnológico e extensão que objetivam o desenvolvimento de TSs e a incubação de empreendimentos econômicos solidários (EES).

Este crescimento das ITCPs corrobora Etzkowitz (2009) no que se refere ao modelo de incubadoras importado dos EUA, que no Brasil foi reinventado, transformando-se em um modelo mais amplo para abordar questões ligadas ao desenvolvimento e à pobreza.

Além das ITCPs, uma instituição que tem atuado na área de tecnologia social é a Fundação Banco do Brasil (FBB). Apoiada na escassez de projetos ou programas e mesmo de artigos e publicações que trabalhem com a conceituação do termo tecnologia social, a FBB lançou em 2001 o Prêmio Fundação Banco do Brasil de Tecnologia Social e o Banco de Tecnologias Sociais (RODRIGUES \& BARBIERI, 2008).

Realizado a cada dois anos, o Prêmio tem por objetivo identificar, certificar, premiar e difundir tecnologias sociais já aplicadas, implementadas em âmbito local, regional ou nacional, que sejam efetivas na solução de questões relativas à alimentação, educação, energia, habitação, meio ambiente, recursos hídricos, renda e saúde. A participação no Prêmio Fundação Banco do 
Brasil de Tecnologia Social é aberta às instituições legalmente constituídas, de direito público ou privado, sem finalidades lucrativas. Em 9 (nove) edições realizadas, de 2001 a 2017, foram recebidas 7020 (sete mil e vinte) inscrições e concedidos mais de $\mathrm{R}$ \$,1 milhões em premiações destinadas ao aprimoramento das tecnologias sociais vencedoras (FBB, 2019).

A partir das iniciativas das ITCPs e da FBB surgem outras, como a criação, em 2002, do Instituto de Tecnologia Social; da Secretaria de Ciência e Tecnologia para Inclusão Social, do Ministério de Ciência e Tecnologia, em 2003; do Centro Brasileiro de Referência em Tecnologia Social, em 2004; e do Centro Avançado de Tecnologias Sociais Ayrton Senna (RODRIGUES \& BARBIERI, 2008).

O ITS (Instituto de Tecnologia Social) Brasil, outro ator neste cenário de TS no Brasil, foi instituído, num contexto em que as demandas do novo milênio desafiavam a sociedade brasileira, a construir um novo modelo de desenvolvimento para viabilizar a relação entre ciência, tecnologia, inovação e inclusão social. Em sua trajetória de mais de 15 anos, o Instituto foi protagonista em processos que colaboraram para o estabelecimento do conceito de tecnologia social e da tecnologia assistiva no Brasil, impulsionando projetos em sua prática pela articulação com governos e sociedade civil (http://itsbrasil.org.br, recuperado em 26 de abril, 2019).

Considerada política pública a partir de 2015, com a aprovação do Projeto de Lei do Senado No 111, DE 2011, que instituiu a Política Nacional de Tecnologia Social com o objetivo de promover, potencializar, organizar, desenvolver, fomentar e fortalecer as atividades de tecnologia social no Brasil, a TS passa a fazer parte da agenda pública e de governo.

Para Dagnino (2014) a TS, deve ser vista como um elemento viabilizador das “sustentabilidades" (econômica, social, política e cultural) dos Empreendimentos Solidários (ESs). Neste contexto, a TS passa a fazer parte da Política Nacional de Educação em Economia Solidária (PNES) como uma prioridade temática no $1^{\circ}$ Plano Nacional de Economia Solidária, para o quadriênio 2015- 2019, no seu eixo Educação e Autogestão, que tem como objetivo principal: 


\title{
Debates Insubmissos
}

Revista

Empreendimento de Economia Solidário - EES), bem como o desenvolvimento e disseminação de tecnologias sociais e de estratégias de comunicação visando fortalecer as práticas da autogestão (PNES, 2015, p.29).

Por meio de seus projetos de ensino, pesquisa e extensão, a Universidade, também ocupa um lugar estratégico nas diretrizes do PNES (2015):

\begin{abstract}
Ensino, pesquisa e extensão universitária amplamente articulados com o Movimento de Economia Solidária e com as políticas públicas de economia solidária com foco na Tecnologia Social, com metodologia autogestionária, a partir da identificação e avaliação das experiências em educação alternativa no meio rural e urbano (PNES, 2015, p.30).
\end{abstract}

É nesta interseção da Tecnologia Social e Economia Solidária que a universidade se faz presente, fomentando a TS, por meio da formação e assessoria a indivíduos que desejem empreender de forma solidária e cooperativa.

\subsection{Como a Universidade tem fomentado a TS e a Economia Solidária}

É principalmente por meio das dimensões do conhecimento, ciência, tecnologia e inovação e educação que as Universidades vêm participando ativamente no promover, potencializar, organizar, desenvolver, fomentar e fortalecer as atividades de tecnologia social no Brasil, mesmo antes da instituição da política.

Para Dagnino (2014) há que se aumentar a "oferta" pelo fomento ao desenvolvimento de TS em Institutos de Pesquisa e Universidades Públicas. As incubadoras tecnológicas de cooperativas populares têm uma participação ainda pequena no desenvolvimento de TS. Para este autor uma medida seria lutar por uma política de apoio tecnológico à Economia Solidária que alocasse em cada incubadora, cooperativa ou empreendimento solidário um profissional para dar suporte cognitivo àquilo que precisa ser feito para superação da pobreza e geração de renda.

Para Martins et al. (2018) um dos lugares onde se observa o desenvolvimento das tecnologias sociais é no âmbito das Universidades. Especialmente nas universidades públicas, não é incomum observar, por meio do desenvolvimento de projetos de extensão ou de inovação, iniciativas cuja metodologia prevê a articulação entre os saberes desenvolvidos no ambiente acadêmico e científico com os saberes locais, da comunidade, do entorno ou de grupos considerados vulneráveis. A partir dessa interlocução, se propiciariam formas (inovadoras ou não) de superar ou mitigar problemas sociais. 
Segundo o NIDES (2019), o Núcleo de Solidariedade Técnica (SOLTEC/UFRJ) interdisciplinar de extensão, pesquisa e ensino, desenvolve a quinze anos projetos em rede com abordagem territorial e participativa, nos campos da Tecnologia Social e da Economia Solidária, visando à construção de políticas públicas para a equidade social e o equilíbrio ambiental. Tendo em sua lista vários projetos em andamento no campo da TS.

Para Roberto, Scariot e Zimmermann (2012) o Projeto de Extensão Incubadora de Economia Solidária, Desenvolvimento e Tecnologia Social - parte do Programa de Extensão Cidadania e Movimentos Sociais da UNIJUÍ - vem constituindo-se em um importante espaço de reflexão e educação, uma vez que oportuniza uma interação cooperativa com diferentes agentes da sociedade civil, bem como uma reflexão crítica sobre os mesmos. Dentre os seus projetos podemos citar a Metodologia de Incubação para EES, que em 2017 conseguiu a certificação de TS, passando a fazer parte do Banco de Tecnologia Social da FBB (https://fbb.org.br/pt-br/, 2019).

Frente a crise atual do país e o reflexo da mesma nas universidades públicas, torna-se cada vez mais importante que as universidades invistam de forma equiparada seus esforços em ensino-pesquisa-extensão na busca da democratização dos seus saberes, contextualizado com os problemas sociais para o desenvolvimento de soluções, contribuindo com o desenvolvimento social e obtendo respaldo da sociedade, visando atender o artigo 207 da Constituição Brasileira de 1988 que dispõe: "as universidades [...] obedecerão ao princípio da indissociabilidade entre ensino, pesquisa e extensão" (MOITA \& ANDRADE, 2009).

A universidade possui um papel vital no debate sobre a exclusão, participando da construção de alternativas e apontando caminhos. Por ser uma instituição criada pela própria sociedade, relaciona-se diretamente com ela de modo que as questões alarmantes da sociedade são igualmente as da universidade (HECKERT, 2004). Porém, para Dagnino (2014) há a necessidade de criar uma agenda diferente da atual, onde uma cultura institucional (da Universidade) viabilize uma agenda, de pesquisa e de formação de recursos humanos, coerente com a inovação social, a economia solidária e a TS. Para este autor, a universidade reforça, de maneira sutil, aparentemente natural, enraizada no mito da neutralidade da ciência e em função do contexto socioeconômico que o engendra, a TC (DAGNINO, 2014). 
Para Etzkowitz e Zhou (2017) ao assumir um novo papel na sociedade, a universidade passa por mudanças internas de forma a integrar novas funções e relações. Para ele, a primeira missão acadêmica da educação inspira uma segunda missão de pesquisa que, por sua vez impulsiona uma terceira missão de desenvolvimento econômico e social. Neste contexto, no Brasil, o desenvolvimento acadêmico pode ter metas simultâneas de negócios e de desenvolvimento social.

A missão da universidade envolve compreender que a tecnologia não se limita apenas àquelas associadas à reprodução do capital, mas à utilização de tecnologias sociais para contextos organizacionais solidários (PINHEIRO, PAULA, \& PAULA, 2014) e que a articulação de diferentes saberes numa residência social pode ser percebida em pelo menos três vertentes: 1) articulação entre saberes científicos e não científicos; 2) articulação entre diferentes atores sociais e os saberes associados a cada um deles; 3 ) articulação entre diferentes áreas do conhecimento científico (SCHOMMER \& FRANÇA FILHO, 2010).

Assim, a partir dessa dimensão de articulação entre ensino, pesquisa e extensão pretendida pela da residência social surge a proposição de uma formação em gestão social que passa, essencialmente, por uma aprendizagem pela prática, a qual envolve, de maneira indissociável, ação e reflexão, que segundo Freire (1987): os homens se fazem pela ação, reflexão e a palavra, enquanto ação e reflexão, resulta na práxis.

\section{METODOLOGIA}

Esta pesquisa, de natureza qualitativa, buscou explorar e descrever as ações universitárias, na UnATI-UERJ, em especial a que pudesse oferecer suporte ao desenvolvimento do cooperativismo popular no estado. Desse modo, caracteriza-se como uma pesquisa de finalidade exploratória e descritiva (GIL, 2008; VERGARA, 2006).

A seleção da UnATI-UERJ atendeu a dois critérios: pelo seu objetivo que visa contribuir para a melhoria dos níveis de saúde físico-mental e social das pessoas idosas, utilizando as possibilidades existentes na instituição universitária por meio de projetos de extensão e pela sua contribuição na transformação do pensar da sociedade brasileira sobre o envelhecimento da população. 


\section{Debates Insubmissos}

Revista

Como meios investigativos, utilizou-se a pesquisa bibliográfica (GIL, 2008; VERGARA, 2006) realizada em artigos, livros, teses e dissertações para discutir conceitos sobre tecnologia social, economia solidária e as atividades universitárias de ensino, pesquisa e extensão.

A coleta de dados se deu também pela observação participante que, segundo Ferreira Deslandes, Gomes e Minayo (2007), pode ser considerada parte essencial do trabalho de campo na pesquisa qualitativa já que, para as autoras, o método permite a compreensão da realidade como estratégia de investigação, uma vez que o pesquisador se coloca como observador de uma situação, com a finalidade de realizar uma investigação, ao mesmo tempo em que participa do processo para colher dados e compreender o contexto da pesquisa. Como instrumento de trabalho, o diário de campo, considerado como uma técnica antropológica (THIOLLENT, 2011), permitiu o registro das informações observadas durante as primeiras aulas do curso que visava obter a percepção do programa oferecido e o engajamento dos participantes ao tema.

Um acompanhamento da aplicação dos conceitos da TS está sendo feito durante o

projeto de extensão, Projetos Solidários, que tem como objetivo promover a transferência de tecnologia social, produzido no meio acadêmico, e oportunizar a integração universidade/sociedade que envolva a participação cidadã (TENÓRIO, 2008) de indivíduos da terceira idade, em projetos de economia solidária.

O relato dos alunos foi a unidade de análise utilizada que foram selecionadas, codificadas e divididas, inicialmente, conforme a Tabela 1.Nela, é apresenta a grade para análise dos relatos segundo a categoria e subcategorias dos temas, bem como os dados a investigar. 
Tabela 1

Grade de análise com categoria, subcategorias e dados a investigar

\begin{tabular}{|c|c|c|}
\hline \multicolumn{3}{|c|}{ Grade de análise } \\
\hline Categoria & Subcategorias & Dados a investigar \\
\hline \multirow{3}{*}{$\begin{array}{c}\text { Extensão universitária } \\
\text { (processo educativo, } \\
\text { aprendizagem pela prática, } \\
\text { identificação de problemas da } \\
\text { sociedade) }\end{array}$} & $\begin{array}{c}\text { Gestão social } \\
\text { (processo gerencial participativo e } \\
\text { autoridade decisória compartilhada } \\
\text { entre os envolvidos na ação) }\end{array}$ & $\begin{array}{l}\text { - Democracia deliberativa } \\
\text { - Ação comunicativa } \\
\text { - Inclusão social } \\
\text { - Esfera pública }\end{array}$ \\
\hline & $\begin{array}{c}\text { Tecnologia social } \\
\text { (transferência de uma tecnologia } \\
\text { social, transformação social, } \\
\text { oportunizando a integração } \\
\text { universidade/sociedade) }\end{array}$ & $\begin{array}{c}\text { - Demanda social } \\
\text { - Inovação social } \\
\text { - Solução de problemas sociais }\end{array}$ \\
\hline & $\begin{array}{c}\text { Economia solidária } \\
\text { (melhoria das condições de vida, } \\
\text { inserção cidadã dentro da sua } \\
\text { comunidade e elaboração de projetos } \\
\text { comunitários) }\end{array}$ & $\begin{array}{l}\text { - Cooperativismo } \\
\text { - Práticas de autogestão } \\
\text { - Ação econômica }\end{array}$ \\
\hline
\end{tabular}

\section{RESULTADOS E DISCUSSÃO}

A UnATI-UERJ iniciou suas atividades em 25 de agosto de 1993, como núcleo da SubReitoria de Assuntos Comunitários da Universidade do Estado do Rio de Janeiro (UERJ) e com um programa destinado à população com idade mínima de 60 (sessenta) anos, sendo as suas atividades inteiramente gratuitas. Este programa visa contribuir para a melhoria dos níveis de saúde físico-mental e social das pessoas idosas, utilizando as possibilidades existentes na instituição universitária.

A UnATI.Uerj conta com uma Coordenação de Projetos de Ensino estruturada em um Centro de Convivência para idosos que oferece cerca de 50 (cinquenta) Cursos/Oficinas livres por ano administrados por uma Coordenação Pedagógica, além de inúmeras atividades abertas como conferências, seminários, fóruns, workshops, palestras, encontros, grupos de estudos, rodas da saúde, aulas abertas, exposições, comemorações, festas temáticas, etc., promovidas pela Coordenação de Eventos Educativos e Socioculturais. Uma Coordenação de Projetos de Extensão que desenvolve atividades multidisciplinares, envolvendo projetos vinculados às unidades de ensino da Uerj, que buscam estes espaços para treinamento de alunos e desenvolvimento de pesquisas. E uma Coordenação de Projetos de Pesquisa que tem estudos 
aprofundados sobre as questões do envelhecimento humano no país e no mundo. É neste contexto de extensão universitária que foi oferecido o curso de projetos solidários.

Com um programa anual, a UnATI-UERJ, oferece cursos e oficinas relacionados as áreas de Educação para a Saúde (22\%), Arte e Cultura (34\%), Conhecimentos Gerais e Línguas Estrangeiras (29\%) e Conhecimentos Específicos sobre a Terceira Idade (15\%) de acordo com a Figura 1.

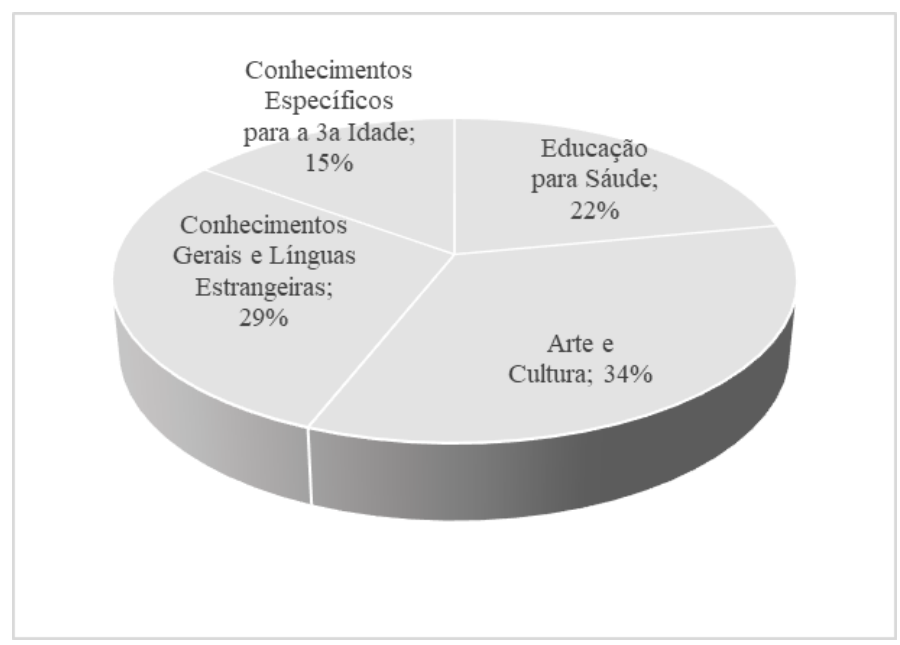

Figura 1:Gráfico dos cursos oferecidos por área de conhecimentos na UnATI-UERJ

Como um projeto de extensão, foi introduzido o curso Projetos Solidários na UnATIUERJ, em março de 2019. Este projeto é ligado ao Centro de Ciências Sociais, da Faculdade de Administração e Finanças da UERJ, em parceria com o programa de Pós Graduação em Administração da Universidade Federal Fluminense e está sendo operacionalizado na UnATIUERJ por meio de uma aluna da graduação em Administração (FAF-UERJ), uma mestranda em Administração (PPGAd-UFF) e um professor pertencente a ambos programas. O curso consta de dois módulos de 30 horas cada: o primeiro, no primeiro semestre de 2019, é dedicado à Economia Solidária abrangendo conceitos, cooperativismo e autogestão, comercialização solidária, finanças solidárias, redes solidárias, empreendimentos solidários, tecnologia social, políticas públicas de economia solidária; o segundo módulo, no segundo semestre de 2019, é focalizado na elaboração de projetos comunitários em que a turma será dividida em pequenos grupos para entender e praticar a elaboração de um projeto de empreendimento solidário. $\mathrm{O}$ 
curso foi categorizado na área de conhecimentos gerais e línguas estrangeiras, sendo o único curso voltado a formação e capacitação dentre outros onze cursos (Tabela 2).

Tabela 2

Relação de cursos categorizados na área de conhecimentos gerais e línguas estrangeiras

\begin{tabular}{l|r}
\hline Cursos & Turmas \\
\hline Academia da Vida & 1 \\
\hline Alemão & 3 \\
\hline Curso de Canção Francesa & 1 \\
\hline Espanhol & 4 \\
\hline Francês & 4 \\
\hline Ingles & 4 \\
\hline Italiano & 4 \\
\hline Leituras e Partilhas: um convite à literatura & 1 \\
\hline Nós na Rede & 1 \\
\hline O Prazer de Ler e Escrever na Terceira Idade & 1 \\
\hline Oficina Elaboração, Interpretação e Publicação de Textos e & 1 \\
Mensagens para Utilização em Mídias Sociais & 1 \\
\hline Projetos Solidários &
\end{tabular}

O curso Projetos Solidários foi oferecido nas condições de um encontro semanal de 2 (duas) horas e duração de 9 (nove) meses (de março a novembro de 2019). A adesão foi de 35 (trinta e cinco) inscritos, correspondente ao número total de vagas ofertadas, tendo comparecido à aula inaugural um total de 15 (quinze) pessoas. A turma composta, em sua maioria, por mulheres já aposentadas ou perto da aposentadoria, que também desenvolvem interesses por artesanato, produtos orgânicos e cuidados com a saúde, buscam na UnATI-UERJ um novo despertar para esta nova fase das suas vidas quando se sentem ativas e produtivas.

As turmas da UnATI-UERJ têm usualmente pessoas de formação acadêmicas diferentes e experiências de vida diversas, o que tornou a apresentação do tema e discussões enriquecedoras, com uma grande participação dos alunos, que tem contribuído com seus relatos e pontos de vista até o momento. Considerando que essas narrativas carregam sentidos e significados quanto a sua formação, experiências, conhecimentos e relevância do tema para cada um deles, a seguir será apresentado uma análise desses relatos, segundo as categorias e subcategorias definidas na metodologia. 
Observou-se a presença dos conceitos sobre inclusão social e democracia deliberativa relativos à Gestão Social, em uma discussão crítica acerca da prática da cidadania (TENÓRIO, 2016). Assim se posicionaram alguns os alunosi: Eu tenho aprendido muito neste curso, aqui passei a ter conhecimento de quanta coisa
tem sido feita para o desenvolvimento social nas comunidades, mesmo que algumas
coisas andem bem devagarinho. (ALUNA 1)

Perto da minha casa tem uma cooperativa de lixo, vou tentar saber se eles trabalham de forma solidária. (ALUNA 2)

Fomos a uma reunião para mulheres empreendedoras e algumas artesãs tinham ótimos produtos, percebemos com os conhecimentos que adquirimos aqui, que se elas se organizassem de forma solidária poderiam ter muito mais chances para gerar renda vendendo seus produtos e se inserir no mercado profissional. (ALUNA 3)

Nesta perspectiva, os relatos durante as aulas, a partir de um processo pedagógico participativo, em que a dialogicidade e entendimento, permite aos alunos demonstrarem interesse sobre os temas, ainda pouco conhecidos por eles, oportunizando uma aprendizagem, a qual envolve, de maneira indissociável, ação e reflexão; e aos educadores permite vivenciar, na prática, a missão da universidade em promover trabalhos em contextos solidários e inclusão social (FREIRE, 1987; BORGES ET AL, 2007,2008).

Sobre a tecnologia social, fomentada pela extensão universitária como um processo educativo, de articulação pedagógica de diferentes saberes e não associados a apenas a reprodução do capital (PINHEIRO ET AL., 2014; SCHOMMER, 2010), assim se posicionaram outros alunos:

Eu não sabia o que é uma tecnologia social, mas acho que estas soluções simples e baratas poderiam ser mais divulgadas. (ALUNO 4)

$\mathrm{Eu}$ vi uma reportagem que estavam usando garrafas pet para resolver alguns problemas nas comunidades, mas não sabia que era chamado de tecnologia social. (ALUNO 5)

Ainda, sobre a apropriação dos conhecimentos em economia solidária e seus pilares cooperativismo, autogestão e ação econômica (SINGER, 2009), que é demonstrado a partir da correlação do que foi aprendido com situações vivenciadas, se posicionaram alguns alunos:

Eu imagino que a economia solidária poderia ser a solução dos nossos problemas atuais. (ALUNO 6) 


\section{Revista \\ Debates Insubmissos}

Eu praticava comércio justo e não sabia! Quando trabalhava numa ONG eu montei um espaço para venda de frutas, de uma associação de pequenas produtoras, e acordava com elas que o preço praticado seria o definido por elas. (ALUNA 7)

Eu tive um quiosque, com duas amigas, em um shopping para vender nosso artesanato, agora entendo por que não deu certo, não pensávamos no coletivo, cada uma só queria ver o seu lado. (ALUNA 8).

A partir destes relatos percebe-se que o programa de extensão, Projetos Solidários, está promovendo um debate dialógico entre a comunidade e universidade, por meio dos alunos, educadores e pesquisadores, propiciando um espaço de educação, reflexão crítica sobre os problemas vivenciados e visualização de possíveis soluções para problemas sociais, em especial para os grupos de terceira idade.

É importante também relatar a experiência dos próprios autores em relação à atividade de extensão. $\mathrm{O}$ autor, coordenador desse projeto, pode vivenciar essa prática em atividades extensionistas parecidas que foram ricamente reportadas em artigos e capítulos de livro (OLIVEIRA ET AL, 2007, SILVEIRA ET AL, 2007, BORGES ET AL, 2008). Essa bagagem acadêmica e de vida foi fonte inspiradora para os autores deste artigo trilhassem o mesmo caminho e pudessem estar dialogando com Paulo Freire (2005), Clodovis Boff (1986) e Tenório (2008) para estarem à frente deste projeto de extensão, Projetos Solidários.

\section{CONSIDERAÇÕES FINAIS}

O curso Projetos Solidários, como uma extensão universitária por meio da transferência de tecnologia social, visou a formação e capacitação de alunos em economia solidária e projetos comunitários. No contexto da UnATI-UERJ, essa proposta mostrou-se ser um processo inovativo, em virtude do pioneirismo da formação em economia solidária para o segmento da terceira idade. Ademais, o interesse da turma demonstrou um grande potencial deste segmento para o desenvolvimento de atividades em economia solidária uma vez que os alunos, com suas experiências de vida, estão mais propensos à cooperação, à solidariedade e à sustentabilidade.

A Gestão Social forneceu os princípios epistemológicos e metodológicos para a concretização desse projeto. A participação de um dos autores, como coordenador do curso Projetos Solidários, em programas de extensão universitária dessa mesma natureza foi 
fundamental para a replicação dessa experiência na atual conjuntura dessas duas universidades públicas, FAF-UERJ e PPGAd-UFF.

A pesquisa também corrobora as políticas públicas, como o PNES, sobre a importância da extensão universitária na articulação do movimento de Economia Solidária para explorar novas alternativas favoráveis ao desenvolvimento social e produtivo, para segmentos excluídos ou carentes, de modo que possam gerar renda de forma autônoma e emancipatória.

Este artigo contribui para demonstrar as possibilidades de aumentar a participação da universidade, por meio de projetos de extensão, na oferta de cursos e projetos ligados ao cooperativismo para terceira idade.

Por fim, ressalta-se a vivências das autoras, uma graduanda em Administração e outra mestranda nessa mesma área, como coparticipantes desse projeto. Elas puderam partilhar da realidade dos grupos que, apesar da idade avançada, encontram-se em sua plenitude de conhecimentos acumulados pela vida e ávidos de poderem colocar em prática suas novas ideias, impulsionadas pelas recentes ferramentas acadêmicas adquiridas.

Nesse sentido, fecha-se o triângulo docência-pesquisa-extensão. A extensão torna-se experiência docente que será consubstanciada posteriormente em seus trabalhos de conclusão de curso e dissertação. Fica, além disso, o sentimento do dever cumprido ao retornar para sociedade o conhecimento conquistado nas universidades públicas.

\section{REFERÊNCIAS}

BENSADON, Ligia. Um estudo sobre a autogestão: os significados de uma prática, In: São Paulo, USP, II Congresso da Rede de ITCPs: Economia Solidária e a Política e a Política da Economia Solidária, 2008.

BORGES, A. C. V. ; OLIVEIRA, Carlyle Tadeu Falcão ; OSIAS, Claudio ; KNOPP, Glauco ; CASTRO, R. M. F. ; VERAS, Thaisa . Gestão Comunitária: uma abordagem prática. 1a. ed. Rio de Janeiro - RJ: FGV Editora, 2008.

BORGES, A. C. V. ; OLIVEIRA, Carlyle Tadeu Falcão ; OSIAS, Claudio ; REZENDE, Cristiane ; KNOPP, Glauco ; CASTRO, R. M. F. ; VERAS, Thaisa . Ensino e Pesquisa em Administração e Gestão Social: uma experiência de interação academia-sociedade In: Airton 
Cardoso Cançado; Jeová Torres Silva Júnior; Paula Chies Schommer; Ariádne Scalfoni Rigo. (Org.). Os Desafios da Formação em Gestão Social. 1 ${ }^{a}$. ed.Palmas -TO: Provisão, v. 2, p. 11445, 2008

BRASIL. PL. $\mathbf{N}^{\circ}$ 111/2011, DE 15 DE OUTUBRO DE 2015. Institui a Política Nacional de Tecnologia Social. Brasília, DF.

BRASIL. PL. $\mathbf{N}^{\circ}$ 3329/2015, DE 15 DE OUTUBRO DE 2015. Institui a Política Nacional de Tecnologia Social. Brasília, DF.

CANÇADO, A. C., TENÓRIO, F. G., \&PEREIRA, J. R. Gestão social: reflexões teóricas e conceituais. In: Cadernos EBAPE.BR, 9(3), 681-703, 2012.

CRUZ, C. C. Tecnologia social: fundamentações, desafios, urgência e legitimidade. 2017, Tese (Doutorado) - Faculdade de Filosofia, Letras e Ciências Humanas. Departamento de Filosofia, Universidade de São Paulo, São Paulo, 2017.

DAGNINO, R. Tecnologia Social: base conceitual; Revist@ do Observatório do Movimento pela Tecnologia Social da América Latina; 2011.

DAGNINO, R. Tecnologia Social: Contribuições conceituais e Metodológicas, Campina Grande, PB:EDUEPB, Florianópolis, SC:Ed. Insular, 2014.

DAGNinO, R., BRANDÃO, F. C., \&NOVAES, H. T. Sobre o Marco Analítico-Conceitual da Tecnologia Social. Tecnologia Social: Ferramenta Para Construir Outra Sociedade, (February), 71-111, 2010

ETZKOWITZ, Henry. Hélice tríplice: universidade-indústria-governo, Porto Alegre: EDIPUCRS, 2009.

ETZKOWITZ, Henry,\&ZHOU, C. Hélice Tríplice: inovação e empreendedorismo universidade-indústria-governo. Estudos Avançados, 31(90), 23-48, 2017.

FEENBERGER, A. A teoria crítica de Andrew Feenberg: racionalização democrática, poder e tecnologia / Ricardo T. Neder (org.). -- Brasília: Observatório do Movimento pela Tecnologia Social na América Latina / CDS / UnB / Capes, 2010.

FERREIRA DESLANDES, Suely \& GOMES, Romeu \& MINAYO, Maria Cecília de Souza. Pesquisa Social. Teoria, método e criatividade. $25^{\mathrm{a}}$ ed. Revista e atualizada. Petrópolis, RJ: Vozes, 2007.

FONSECA, P. A virada deliberativa nos estudos sociais da ciência e tecnologia e seus reflexos para novos regimes de inovação. Liinc Em Revista, 8(1), 151-164. https://doi.org/10.18225/liinc.v8i1.467, 2012 
FRAGA, Lais, SILVEIRA, Ricardo,\&VASCONCELLOS, Bruna. O engenheiro educador. In: São Paulo, USP, II Congresso da Rede de ITCPs: Economia Solidária e a Política e a Política da Economia Solidária, 2008

FREIRE, P. Pedagogia do Oprimido, 17 ed. Rio de Janeiro: Paz e Terra, 1987.

FREITAS, C. C. G.,\&SEGATTO, A. P. Ciência, tecnologia e sociedade pelo olhar da Tecnologia Social: um estudo a partir da Teoria Crítica da Tecnologia. Science, technology and society from the perspective of Social Technology: a study from the Critical Theory of Technology. Abr, 12(7), 302-320, 2014. Disponível em: https://doi.org/10.1590/1679-39517420

FBB - Fundação Banco do Brasil. Banco de Tecnologias Sociais. Disponível em: https://fbb.org.br/pt-br/, 2019

GIL, Antônio Carlos. Métodos e técnicas de pesquisa social, São Paulo: Atlas, 2008.

HECKERT, Sônia Maria Rocha. A emergência e potencialidades da economia solidária e autogestão no contexto das transformações do mundo do trabalho: a participação da Universidade, Brasília Mercado de Trabalho - Conjuntura e Análise, Brasília, v. 24, p.78, ago, 2004. Disponível em: http://www.ipea.gov.br/portal/index.php?option=com content\&view $=$ article $\&$ id $=5703$

INSTITUTO BRASILEIRO DE GEOGRAFIA E ESTATÍSTICA (IBGE). Síntese de Indicadores Sociais: uma análise das condições de vida da população brasileira. Rio de Janeiro, 2013

ITS BRASIL. Instituto de Tecnologia Social. Disponível em:http://itsbrasil.org.br, 2019

LASSANCE, A. E., Mello, C. J., Barbosa, E. J. S., Jardim, F. A., Brandão, F. C., \& Novaes, H. T. (2004). Tecnologia social uma estratégia para o desenvolvimento, Fundação Banco do Brasil; Rio de Janeiro, 2004.

LOPES, W. E. S. Andrew Feenberg e a bidimensionalidade da tecnologia. Revista de Filosofia: Aurora, 27(40), 111-142. https://doi.org/10.7213/aurora.27.040.DS05, 2015

MARTINS, L.P.B., ANTUNES, L.R., PINHO DA SILVA, Esther, \&PEREIRA DA SILVA, E; L..(2018). Tecnologias Sociais, seus usos e significados: A Experiência do Catálogo de Tecnologias Sociais da Universidade Federal Fluminense. In: Anais do XI CASI - Congresso de Administração, Sociedade e Inovação. Anais...Rio de Janeiro(RJ) ECEME. Disponível em: $\quad<\mathrm{https} / / \mathrm{www}$.even3.com.br/anais/11casi/119142-TECNOLOGIAS-SOCIAIS-SEUSUSOS-E-SIGNIFICADOS---A-EXPERIENCIA-DO-CATALOGO-DE-TECNOLOGIASSOCIAIS-DA-UNIVERSIDADE->. Acesso em: 01/03/2019 
MOITA, Filomena \&DE ANDRADE, Fernando. Ensino-pesquisa-extensão: um exercício de indissociabilidade na pós-graduação; Revista Brasileira de Educação v. 14 n. 41 maio/ago, 2009.

MORGADO, Ana Paula, PLIOPAS, Ana L. Desenvolvendo profissionais para o futuro, Fundação Getúlio Vargas, GVExecutivo, V 17, N 4, Jul/Ago, 2018.

NÚCLEO INTERDISCIPLINAR PARA DESENVOLVIMENTO SOCIAL (NIDES).Disponível em: http://nides.ufrj.br/index.php/programas/soltec, 2019

OLIVEIRA, C. T. F., TELES, Bárbara, RODRIGUES, Edgard, \& CHAVÃO, Norma. (2018). O papel das universidades no fomento às políticas públicas de Economia Solidária no Estado do Rio de Janeiro. In: Anais do XI CASI - Congresso de Administração, Sociedade e Inovação. Anais.Rio de Janeiro(RJ) ECEME. Disponível $\mathrm{em}:<\mathrm{https} / / \mathrm{www}$.even3.com.br/anais/11 casi/119066-O-PAPEL-DAS-UNIVERSIDADESNO-FOMENTO-AS-POLITICAS-PUBLICAS-DE-ECONOMIA-SOLIDARIA-NOESTADO-DO-RIO-DE-JANEIRO>. Acesso em: 01/03/2019

PINHEIRO, D. C., PAUlA, A., \&PAULA, P. De. A Mitologia da Ineficiência nas Organizações Solidárias : em Busca da Ressignificação de um Conceito, 42-65, 2014.

REDE DE CENTROS DE FORMAÇÃO E APOIO A ASSESSORIA TÉCNICA EM ECONOMIA SOLIDÁRIA. Nossa prática, nossa riqueza. Revista de Sistematização de experiências de Educação em Economia Solidária. Convênio n $n^{\mathbf{7}} \mathbf{7 7 5 . 1 8 2} / 2012$. Cáritas Brasileira/SENAES/MTPS. Brasília, 2015.

ROBERTO, Jaqueline; SCARIOT, Nádia;\&ZIMMERMANN, Ieda. A Economia Solidária e a ITECSOL/UNIJUÍ: produção e interlocução de conhecimentos, 2012.

RODRIGUES, I., \&BARBIERI, J. C. A emergência da tecnologia social : revisitando o movimento da tecnologia apropriada como estratégia de desenvolvimento sustentável, 42(6), 1069-1094, 2008.

SANTOS, Boaventura de Sousa. Pela mão de Alice. O social e o político na pósmodernidade, $7^{\text {a }}$ edição, 1999.

SILVEIRA, A. C. P. ; BORGES, A. C. V. ; OLIVEIRA, Carlyle Tadeu Falcão ; OSIAS, Claudio ; REZENDE, Cristiane ; KNOPP, Glauco ; CASTRO, R. M. F. ; VERAS, Thaisa . Gestão Social: uma experiência de integração academia-sociedade. In: TENÓRIO, Fernando Guilherme. (Org.). Gestão Social: metodologia, casos e prática. $5^{\mathrm{a}}$ ed.Rio de Janeiro: Editora FGV, 2007.

SINGER, P. Introdução à economia solidária. São Paulo. Fundação Perseu Abramo, 2003. 
SINGER, P. Políticas públicas da Secretaria Nacional de Economia Solidária do Ministério do Trabalho e Emprego. In: Mercado de Trabalho: conjuntura \& análise, 39, Brasília: Ipea/MTE, pp. 43-48, 2009

SCHOMMER, P. C., \&FRANÇA FILHO, G. C. A metodologia da Residência Social e a aprendizagem em comunidade de prática. Revista Eletrônica Da Residência Social Do CIAGS/UFBA, 1(1), 203-226, 2010

TENÓRIO, F. G. Gestão Comunitária: uma abordagem prática, FGV Editora, Rio de Janeiro, 2008.

TENÓRIO, F. G. Uma alternativa: gestão social, Ed. Unijuí, Ijuí, 2016.

THIOLLENT, Michel. Metodologia da pesquisa-ação. 18. ed. São Paulo: Cortez, 2011.

i Os nomes dos alunos do curso Projetos Solidários foram omitidos, garantindo a confidencialidade dos relatos.

Submetido em: 08/07/2019

Aprovado em: 04/08/2019 